\title{
Two years of the Critical Ultrasound Journal and still going...
}

\author{
Michael Blaivas
}

Published online: 24 November 2010

(C) Springer-Verlag 2010

One of the most important offsprings of WINFOCUS is the Critical Ultrasound Journal (CUJ). This endeavor took years to bring to reality and continues to challenge the WINFOCUS team. Yet, it is critical to our overall visions and mission. As the final issue of our second year in existence is at hand, it is important to recognize the great achievement that the CUJ represents and how many people have labored hard to make it a reality. The recent editorial board meeting at Rome during the sixth WINFOCUS World Congress was an important milestone. The large meeting room was filled, and a robust discussion about the journals achievement, progress and future threatened to run into the next scheduled time frame for the room. It was clear from Springer presentations and editorial board comments that the journal is doing well, perhaps better than expected, but there is more work to be done as we seek to attract increasing submission numbers and those of higher quality.

Perhaps, the greatest challenge for the CUJ is continued pursuit of listing on the PubMed index. There are many indexing tools, but this free service is available to potential readers all over the world and appears to be one of the most popular among researchers and clinicians. The path to being indexed is not an easy one, and we may not even be ready to apply for another year. However, I think it is critical for a number of reasons. Not only is visibility important so that our message reaches all over the world, but sustaining a healthy journal in today's electronic age would be difficult without it. Many of the accomplished researchers who have already published in the CUJ and those who are considering publication are effectively in competition with others to have their research seen by their peers first. After all, it seems that until something is published and available in print it does not exist. This is probably much to the frustration of many accomplished sonologists who have personally developed new applications, performed local studies showing ultrasound efficacy and fine-tuned their ultrasound practice to be more efficient than others around them. However, to get credit for new developments, approaches and thoughts, they have to be put down in print. Next, however, they have to be available for others to find, see and read. While this seems obvious, it is no longer practical to just publish. Others have to be able to find your publication without significant difficulty. With the number of journals published in the world well over 5,000 , being listed by key indexing services is critical.

Over the next few months, we will again review our options for becoming indexed on PubMed. Our options include the standard application approach or considering becoming an open access journal. Although many pros and cons have to be weighed, this is an important issue to tackle. In response to a call for articles, we have had multiple new submissions of increasing quality. I am hoping to reward our authors and readers with indexing on PubMed as soon as possible.

Thank you again for your support as readers, authors and editorial board members.

Michael Blaivas

Editor-in-Chief
M. Blaivas $(\bowtie)$

Department of Emergency Medicine,

Northside Hospital Forsyth, Cumming, GA 30040, USA

e-mail: mike@blaivas.org 